\title{
Discussions on Auditory-Perceptual Evaluation Performed in Patients With Voice Disorders
}

\section{Seung Jin Lee (D)}

Division of Speech Pathology and Audiology, Research Institute of Audiology and Speech Pathology, College of Natural Sciences, Hallym University, Chuncheon, Korea

\section{음성장애 환자에서 시행되는 청지각적 평가에 대한 논의}

이승진

한림대학교 자연과학대학 언어청각학부 및 청각언어연구소

The auditory-perceptual evaluation of speech-language pathologists (SLP) in patients with voice disorders is often regarded as a touchstone in the multi-dimensional voice evaluation procedures and provides important information not available in other assessment modalities. Therefore, it is necessary for the SLPs to conduct a comprehensive and in-depth evaluation of not only voice but also the overall speech production mechanism, and they often encounter various difficulties in the evaluation process. In addition, SLPs should strive to avoid bias during the evaluation process and to maintain a wide and constant spectrum of severity for each parameter of voice quality. Lastly, it is very important for the SLPs to perform a team approach by documenting and delivering important information pertaining to auditory-perceptual characteristics in an appropriate and efficient way through close communication with the laryngologists.

Keywords Voice disorders; Dysphonia; Auditory-perceptual evaluation; Voice quality; Speech-language pathologist.

\section{서 론}

음성장애에 대한 평가는 반드시 다면적이고 종합적으로 이루어져야 한다[1]. 이는 같 은 중증도의 음성장애를 가진 환자라 할지라도, 주관적인 불편감이나 삶의 질 저하의 정도, 일상이나 사회생활에 미치는 영향, 음성 활동에 참여하지 못하는 제약의 정도 등 이 환자에 따라 다를 수 있기 때문이다. 특히 음성질환을 보이는 환자들 중에서 조조성 (roughness)이나 기식성(breathiness), 다소의 노력성(strain) 등 감기에 걸렸거나 음성 을 오남용했을 때 누구나 일시적으로 겪게 되는 형태나 정도의 음성 특성이 아니라, 청 지각적으로 다소 이례적이거나 눈에 띄는 특성을 보이는 경우 이러한 영향은 더욱 심 각한 것이 될 수 있다. 예컨대 연축성 발성장애(spasmodic dysphonia)는 지속적인 것 이 아닌 간헐적인 노력성과 더불어 발성의 끊김(voice breaks)을 동반하는데, 이러한 신경학적 음성장애 환자는 동일한 중증도를 가진 기능적 혹은 기질적 음성장애 환자에

\begin{abstract}
Received June 12, 2021
Revised June 30, 2021

Accepted July 6, 2021
\end{abstract}

\section{Corresponding Author}

Seung Jin Lee, PhD

Division of Speech Pathology and

Audiology, Research Institute

of Audiology and Speech Pathology,

College of Natural Sciences,

Hallym University,

1 Hallymdaehak-gil,

Chuncheon 24252, Korea

Tel +82-33-248-2223

$\mathrm{Fax}+82-33-256-3420$

E-mail sjl@hallym.ac.kr

\section{ORCID iD}

Seung Jin Lee (1)

https://orcid.org/0000-0001-6200-0004

This is an Open Access article distributed under the terms of the Creative Commons Attribution Non-Commercial License (https://creativecommons.org/ licenses/by-nc/4.0) which permits unrestricted non-commercial use, distribution, and reproduction in any medium, provided the original work is properly cited. 
비해 음성 활동에 실제 참여하는 데 더 큰 제약을 느끼며, 일 상생활에서 느끼는 불편감이 더욱 큰 것으로 보고되었다[2]. 이는 부분적으로는 음성의 기능 자체가 본질적으로 본인 혹 은 다른 사람에게 지각되는 현상(perceptual phenomenon) 이기 때문이기도 하다.

이러한 측면에서 보면 여러 평가 양식 중 가장 중요한 시금 석으로 여겨지는 것이 숙련된 전문가의 청지각적 평가 결과라 는 점은 그리 놀랄 만한 일은 아니다. 즉 음성장애 분야의 전문적인 지식과 임상경험을 가진 언어재활사(speech-language pathologist, SLP)나 이비인후과 전문의와 같은 전문 가가 대상자에 대한 정확한 배경정보를 숙지하고 청지각적 평 가에 대한 충분한 숙련도만 갖춘다면, 주관적인 평가 과정을 통하여 비교적 낮은 비용과 높은 시간적 효율성을 가지고 음 성 상태에 대한 신뢰도와 타당도가 높은 평가를 수행할 수 있는 것이다[3]. 뿐만 아니라 여타 양식의 평가 과정을 통해서 는 얻기 어려운, 임상적으로 음성질환의 관리와 중재에 의미 있는 여러 부가적인 정보를 알 수 있다는 큰 장점이 있다고 말할 수 있다.

그러나 청지각적 평가를 실제 임상현장에서 음성장애 환자 를 대상으로 시행할 때 마주치게 되는 여러 문제가 있으며, 이는 환자에 대한 정확한 평가와 중재에 어려움을 야기하는 요인이 될 수 있다. 이비인후과 음성클리닉에서 마주치는 음 성장애 환자가 신경학적 이슈 등 다른 의학적 문제들을 가지 고 있을 가능성이 있는 경우 이러한 문제는 더욱 가중된다. 나아가 음성장애 연구에 있어서도 이러한 문제가 이어져 연 구 데이터에 대한 해석을 어렵게 하는 요인이 되고는 한다. 따 라서 이러한 문제에 대한 전문가 그룹의 토의를 통하여 발전 적인 개선 방안을 마련하고, 일정한 가이드라인을 제시하는 일은 매우 중요하다고 할 수 있다. 이를 통하여 임상 및 연구 에서 주관적 평가 양식인 청지각적 평가의 유용성을 제고하 고, 음성장애에 대한 정밀하고 다면적 평가를 가능케 함으로 써 빠르고 정확한 진단에 이바지할 수 있다.

이에 지난 2020년 11월 7일 대한후두음성언어의학회 제8 회 음성연수회에서는 '음성장애 환자에서 말 특성에 대한 청 지각적 평가라는 주제로 패널 토의를 진행하여 청지각적 평 가 과정에서 겪게 되는 여러 가지 문제들을 논의하였으며, 이 를 통하여 음성장애의 임상 및 연구 분야에서의 이슈들에 대 한 다양한 의견을 청취하고 일정한 컨센서스를 형성하였다. 따라서 본고에서는 이비인후과 음성 클리닉의 임상 실제와 음성장애 분야의 연구 과정에서 음성 및 말 장애에 대한 청 지각적 평가를 수행하면서 임상가 혹은 연구자가 마주치게 되는 여러 이슈들에 대한 전문가 의견들을 정리하여 보고자 한다.

\section{본 론}

패널 및 토의 주제의 구성

본 패널 토의에는 임상 및 연구 측면에서의 다양한 주제를 토의하기 위해 임상 및 연구 분야의 전문가들이 골고루 참여 하였다. 구체적으로는 대학병원 이비인후과 음성클리닉 임상 현장에서 풍부한 임상경험을 가지고 있는 언어재활사 4 인, 그 리고 임상경험과 더불어 대학 언어병리학 전공 학과에서 재직 하며 교육 및 연구 경험이 풍부한 교수 2 인이 패널로 참여하 였다. 토의 주제로는 말 산출 과정을 토대로 호흡, 발성, 공명, 조음, 운율의 측면에서 청지각적 평가와 관련된 이슈들을 짚 어가며 토의하였다.

\section{호흡 측면}

\section{비정상적인 호흡 패턴의 청지각적 평가}

음성장애 환자 가운데에는 여러 기질적 혹은 기능적 원인 으로 인하여 청지각적으로 비정상적인 호흡 패턴을 보이는 경우가 매우 많다. 예컨대 양측성 성대마비(bilateral vocal fold palsy), 성문하 협착(subglottic stenosis), 후두 유두종(laryngeal papilloma) 등으로 인해 기도가 충분히 개방(patent)되 지 않은 환자의 경우, 좁아진 틈 사이로 흡기 시 소음(inhalation noise)이 청취되는 등 비정상적인 호흡 패턴이 관찰되는 임상 케이스가 흔하다. 또한 인후두 역류질환(laryngopharyngeal reflux)이나 알레르기 비염(allergic rhinitis) 등의 만 성적인 후두 자극과 과민해진 후두로 인해 발생하고 심인성 원인에 의해 악화되기도 하는 역행성 성대 운동 장애(paradoxical vocal fold movement disorders) 환자의 경우 흡기 발성(inhalation phonation)을 주의 깊게 관찰해야 하며, 호 흡기 등과 협력하여 주된 원인을 탐색하게 될 수 있다는 점을 염두에 두어야 한다. 해외에서는 역행성 성대 운동 장애나 만 성 기침(chronic cough)에서 기능적인 병인 요소가 강하다고 판단되면 SLP가 행동적 치료를 담당하는 경우가 많다[4-6].

뿐만 아니라, 반회후두신경(recurrent laryngeal nerve)의 기능에 영향을 줄 수 있는 갑상선 수술이나 흥부외과의 수술 이후에 발생하는 편측성 성대마비의 경우 음성 교육과 음성 관리가 필요할 수 있다. 또 발성의 효율성이 저하되어 한 호 흡 단위(breath group)에 산출할 수 있는 말의 길이가 감소하 고 후두 근육이 긴장되면서 '짧은 구(short phrases)'의 특성을 보이기도 한다[7,8]. 이 경우 짧은 말 과제나 모음에서는 호흡 의 문제가 잘 드러나지 않다가도 문단 읽기 등의 연결발화 (connected speech) 산출 과제에서 드러나는 경우가 많으므 로 이를 고려할 필요가 있으며, 면밀한 관찰과 함께 일상생활 
에서의 증상을 상세히 청취하는 일 또한 중요하다. 복식호흡 등을 통한 적절한 호흡 조절을 독려하고, 과도한 성문상부의 과기능적 보상작용을 방지하기 위한 음성치료와 더불어 경 우에 따라서는 성대 주입술(injection laryngoplasty)의 가능 성도 고려될 수 있다는 점을 염두에 두어야 한다[9-12]. 또한 호흡 측면에서 이러한 청지각적 특성이 관찰될 경우, 통상적 으로 기록하는 grade, roughness, breathiness, asthenia, strain (GRBAS)[13]나 Consensus Auditory-Perceptual Evaluation of Voice $(\mathrm{CAPE}-\mathrm{V})[14]$ 등의 청지각적 평가 결 과 외에 별도로 잘 기록하여 이비인후과 진료를 수행하는 전 문의에게 잘 전달될 수 있도록 해야 한다는 점에 모든 패널 이 동의하였다.

\section{발성 측면}

\section{GRBAS를 이용한 음성의 질 평가}

음성의 질(voice quality)에 대한 평가 도구 중 가장 많이 사 용되는 도구 중의 하나가 GRBAS 척도이다[13]. GRBAS 척도 가 오랜 기간 동안 전 세계적으로 임상에서 널리 이용되어 온 이유 중 하나는 검사자의 숙련도에 비교적 영향을 덜 받으며, 평가자 간 신뢰도가 높고, 시행이 비교적 용이하다는 점이다. 그러나 GRBAS 척도는 음도나 강도와 같은 측면을 반영하지 못하고, 신뢰도가 높은 대신 미세한 변화나 증상의 일관성 측 면을 평가하기에 다소 부적절할 뿐만 아니라, 질환에 특화된 평가가 어렵다는 단점도 가지고 있다. 본 패널 토의에 참여한 대부분의 패널들 또한 이러한 문제점을 인식하고 있었으며, 이 를 일부 보완하기 위해 RBAS 척도를 먼저 평가한 뒤, 음도나 크기 등 GRBAS에 반영되지 않는 특성들을 종합하여 $\mathrm{G}$ 척 도를 평정하는 방법에 동의하였다. 아울러 다수의 패널들은 증상이 일정한 정도나 시도 치료(trial therapy) 시의 개선 정 도, 즉 자극반응도(stimulability) 등은 척도 평가와 별도로 기 록하는 것이 좋다는 의견을 제시하였다.

GRBAS는 $0,1,2,3$ 점의 4점 등간 리커트 척도를 이용하 기 때문에 간헐적(intermittent)으로 해당 척도의 중증도가 증 가하거나, 중재 전후 변화의 폭이 크지 않은 경우 이를 타당하 게 반영하기 어렵다. 따라서 비록 어떠한 교과서에도 명시되 어 있지 않음에도 불구하고 많은 수의 임상가와 연구자들이 각 척도 사이의 0.5 척도를 사용해왔으며, 본 패널 토의에 참 여한 패널들도 전원 0.5 척도를 사용하는 것으로 보고하였 다. 즉 0.5 는 정상-약함, 1.5 는 약함-중간, 2.5 는 중간-심함의 척도로 활용하여 $0,0.5,1,1.5,2,2.5,3$ 의 7점 척도를 활용 하는 것이다. 또한 비슷한 맥락에서 많은 연구자들은 7점 척 도를 사용하여 범주형 변수가 아닌 연속형 변수로 취급하여 t-검정, 분산분석, 다중회귀분석 등에서 종속변수로 사용해 왔으며, GRBAS 평가결과는 비모수, CAPE-V 평가결과는 모 수적인 통계방법을 사용하여 분석하기도 한다[15]. 이 이슈에 대한 실증적인 연구로서 최근 Choi 등[16]은 GRBAS를 7점 척도와 4점 척도를 사용하여 평가한 경우를 비교하였는데, 7점 척도의 신뢰도 또한 4점 척도에 비해 다소 낮으나 양호(fair) 한 수준이었으며, 음향학적 측정치와의 상관관계를 토대로 볼 때 7점 척도가 4점 척도에 비해 중증도 간의 차이를 더욱 잘 반영하는 것으로 보고되었다. 이러한 장단점을 고려하면 7점 척도를 활용한 GRBAS 척도의 사용은 임상 및 연구에서 충 분히 의미를 가진다고 결론지을 수 있다.

또 한 가지 GRBAS 척도에서 꾸준히 논란이 되어 온 것은 무력성(asthenia) 척도이다. 무력성 척도는 흔히 기식성 척도와 혼동되거나 신뢰도에서 문제시되는 경우가 많으며 $3,17,18]$, 이로 인해 다수의 연구들은 $\mathrm{A}$ 척도를 아예 배제하고 수행하 기도 한다[19-22]. 가장 문제가 되는 점은 무력성의 본질인 '약 한 음성(weak voice)'의 본질에 대한 정의가 불분명하다는 데 있다. 즉 임상가나 연구자에 따라 어떤 전문가는 '약한 음성' 의 본질을 '음성의 강도가 감소한 것'에서 찾을 수도 있는 반 면, 다른 전문가는 가성(falsetto)의 경우와 같이 발성 시 성대 의 접촉 면적이 감소하는 성구(vocal register)의 변화에서 찾 을 수도 있다. 패널들의 의견에 따르면, 이러한 차이는 특정 질 환, 예컨대 변성기 발성장애(mutational falsetto), 기능적 실성 증(functional aphonia) 등의 여부에 대한 임상가의 사전 인 지에 따른 편향이나 대상자의 개별적 특성에 따라 더욱 심화 될 수 있으며, 결과적으로 평정의 신뢰도를 저하시키고 리커 트 척도의 한계[3]와 상호작용하여 GRBAS 척도의 유용성 자 체를 저하시키는 것으로 보인다.

그러나 무력성 척도는 특정 질환의 경우 그 유용성이 있을 수 있다. 예컨대 다발성 경화증(multiple sclerosis) 환자에서 환자의 중증도를 평가하는 확장 장애 상태 척도(Expanded Disability Status Scale) 점수가 바로 이 무력성 점수와 중등 도의 상관관계를 보이는 것으로 보고되었는데[23], 이는 사지 뿐만 아니라 발성 메커니즘에 관여하는 다양한 근육의 약화 를 보일 수 있는 중증 근무력증(myasthenia gravis)이나 근위 축성 측삭 경화증(amyotrophic lateral sclerosis), 파킨슨병 (Parkinson's disease) 등과 같은 신경퇴행성 질환에서 무력 성을 더욱 면밀하게 살펴보아야 할 필요성을 시사한다. 비록 이비인후과 음성클리닉에서 자주 볼 수 있는 환자군은 아니 지만, 신경학적 검사를 거쳐 신경과에서 최종 진단이 이루어 지지 않은 환자가 발음 혹은 음성문제를 주소로 이비인후과 에 먼저 내원할 경우, 신경과와의 협진이 이루어지는 병원의 세팅에 따라 SLP가 이비인후과에만 근무하는 경우, 이비인 
후과 SLP의 음성평가 결과를 신경과 전문의가 진료 및 감별 진단 시 참고할 가능성이 있는 경우를 고려할 때, 특히 무력성 이 특징적으로 관찰되는 환자의 경우 이에 대한 보다 세밀한 평가가 이루어질 필요가 있는 것이다.

\section{$\mathrm{CAPE}-\mathrm{V}$ 를 이용한 음성의 질 평가}

$\mathrm{CAPE}-\mathrm{V}$ 는 언어재활사와 음성과학자 그룹이 미국 말언어청 각협회(American Speech-Language-Hearing Association, $\mathrm{ASHA}$ )의 후원을 받아 컨퍼런스를 거쳐 제작하고 검증 및 개 선 작업을 거친 평정 척도이다. 최근 전 세계적으로 GRBAS 를 대체하여 사용되고 있으며, GRBAS와는 달리 표준화된 프 로토콜이 연구되어 신뢰도와 타당도가 검증되었다[3,14,24]. 특히 GRBAS 척도의 여러 단점을 고려하여 기존의 음질 관 련 변수 중 무력성을 제외하고 음도(pitch) 및 크기(loudness) 측면을 추가하여 시각아날로그척도(visual analogue scale, $\mathrm{VAS}$ )를 이용하여 평정하도록 하였다[14]. 특히 이중 전반적 중증도(overall severity) 척도는 여러 연구들에서 음성장애 의 중증도를 대표하는 척도로서 널리 이용되어 왔다[25-28]. 다만 비전문가에서도 상당 수준의 신뢰도를 보이는 GRBAS 와는 달리, $\mathrm{CAPE}-\mathrm{V}$ 는 청자의 청지각적 평가 경험이 신뢰도 에 매우 큰 영향을 미치므로, 임상 및 연구에서 사용 시 이를 고려하여야 한다[29].

$\mathrm{CAPE}-\mathrm{V}$ 의 각 척도에 대하여 정상에서 벗어난 정도( $\mathrm{de}^{-}$ gree of deviancy)에 대한 평정을 한 결과는 0-100 사이의 정 수로 산정된다. 그리고 이 범위 안에는 약한 정도의 이상(mildly deviant), 중간 정도의 이상(moderately deviant), 심한 정도의 이상(severely deviant) 등 중증도 수준에 대한 기준점(severity indicator)이 존재한다. 그런데 문헌에 따라 각 기준점이 되는 점수가 상이하다. 즉 약함, 중간, 심함의 정도에 대한 기 준점이 각각 $20,40,70$ 점[17,30,31] 혹은 10,50 , 90점[14,3234]으로 적용된 문헌들이 각각 존재한다. 가령 15점으로 평정 된 대상자의 경우 전자의 기준으로는 정상-약함으로 평정된 것인 반면, 후자의 기준에서는 약함-중간으로 평정된 것이다. 어느 기준이 더 우월하다고 단정짓기는 어려우나, 현재 ASHA 의 공식홈페이지의 CAPE-V 다운로드 페이지(https://www. asha.org/form/cape-v/)에서 제공하는 양식은 $10,50,90$ 점 기준점을 채용하고 있다. 본 패널 토의에서는 두 가지 기준점 을 사용하는 패널들이 모두 존재하였으나, 이러한 기준점이 혼용되어서는 안되며, 연구자료나 임상자료에 대한 해석 시 어떠한 기준점을 사용하였는지 잘 살펴야 한다는 점에 모든 패널이 동의하였다. 특히 $20,40,70$ 점을 기준점으로 사용한 최근 한 연구에서는 중증도 간 절단점(cutoff score)이 각각 $27,52,71$ 점으로서 평가 시 중증도의 기준점과 상당히 일치
하는 것으로 나타나 이러한 기준점 사용의 중요성과 임상적 유용성을 뒷받침하였다[30].

$\mathrm{VAS}$ 는 수행 절차의 특성상 별도의 프로그램이나 앱 등의 측정 수단이 없다면, 임상에서 시행하기에 다소 번거로운 길 이 측정 절차를 거쳐야 하며, 검사지를 물리적으로 안전하게 보관하여야 하는 부담도 있다. 이 경우 엑셀시트를 활용하면 측정에 소요되는 노력을 줄이고, 디지털화된 결과를 쉽게 저 장 및 관리할 수 있다(Fig. 1). 즉 빈 양식에 먼저 화살표를 옮 겨 평정을 시행한 후, 그 양식에 눈금 모양의 셀을 덮어씨워 쉽게 값을 측정할 수 있다.

음성의 질에 대한 청지각적 평가에서는 일관성은 최대화하 되, 편향(bias)을 최소화하고자 하는 노력이 지속적으로 이루 어져야만 한다. 가령 합성 음성이나 실제 대상자의 음성을 청 각적 기준점(auditory anchors)으로 활용한 반복적이고 광범 위한 훈련을 통해 장애 음성에 대한 청지각적 평가의 신뢰도 를 제고할 수 있는 것으로 보고되었다[31,35,36]. 특히 수술적 혹은 행동적 치료 전후 여러 차례 평가를 통하여 변화 추이 를 지속적으로 추적검사하는 경우, 이전의 청지각적 평가 결 과와 음성샘플을 기준점으로 삼을 수 있도록 기록을 잘 관리 하는 일이 필요하며, 본 패널 토의에서도 모든 패널들이 중재 후 평가 시 이전의 결과를 참조하는 것으로 나타났다. 또한 환자가 술 후 본인 음성이 개선된 정도에 인식이 부족할 때 이 러한 샘플을 들려주고 청지각적 평가 결과를 함께 제시하면 환자의 만족도를 높이는 데 도움이 된다는 의견도 제시되었 다. 뿐만 아니라 특히 심인성 음성장애에서 환자가 상황, 조건 에 따라 현저하게 다른 음성 증상을 보이는 경우, 가급적 문 제가 잘 드러나는 상황에서의 음성 상태를 확인할 수 있도록 노력해야 한다는 점에도 패널들이 동의하였다.

\section{청지각적 평가에 이용되는 말 자료}

전술한 바와 같이 CAPE-V의 경우 표준화된 말 자료와 프 로토콜이 각 나라별로 존재한다[32-34,37-39]. 우리나라 음 성장애 분야 SLP의 임상실제에 대한 한 연구에 따르면, 청지 각적 평가 시 모음 연장발성 과제와 함께 성인의 경우 '가을, '산책' 등의 표준 문단을 사용하거나(69\%), 자체 제작한 문장이 나 문단을 사용하는 경우(14\%)가 많았으며, 본 패널 가운데 에는 두 표준 문단을 사용하는 패널의 비율이 거의 동일하였 다[40]. 다만 표준 문단의 경우 많은 기관에서는 시간적 효율 성을 제고하기 위해, 혹은 기술적인 이유로 문단의 전체를 읽 기보다는 일부만 읽거나 제한 시간을 두어 기록하는 경우가 많고, 본 패널 토의에 참여한 패널들 대부분도 문단의 일부, 특히 앞부분의 1-2개 문장을 사용한다고 보고하였다. 그러나 국내 선행연구에서 '가을' 문단의 앞부분, 중간부분, 뒷부분 


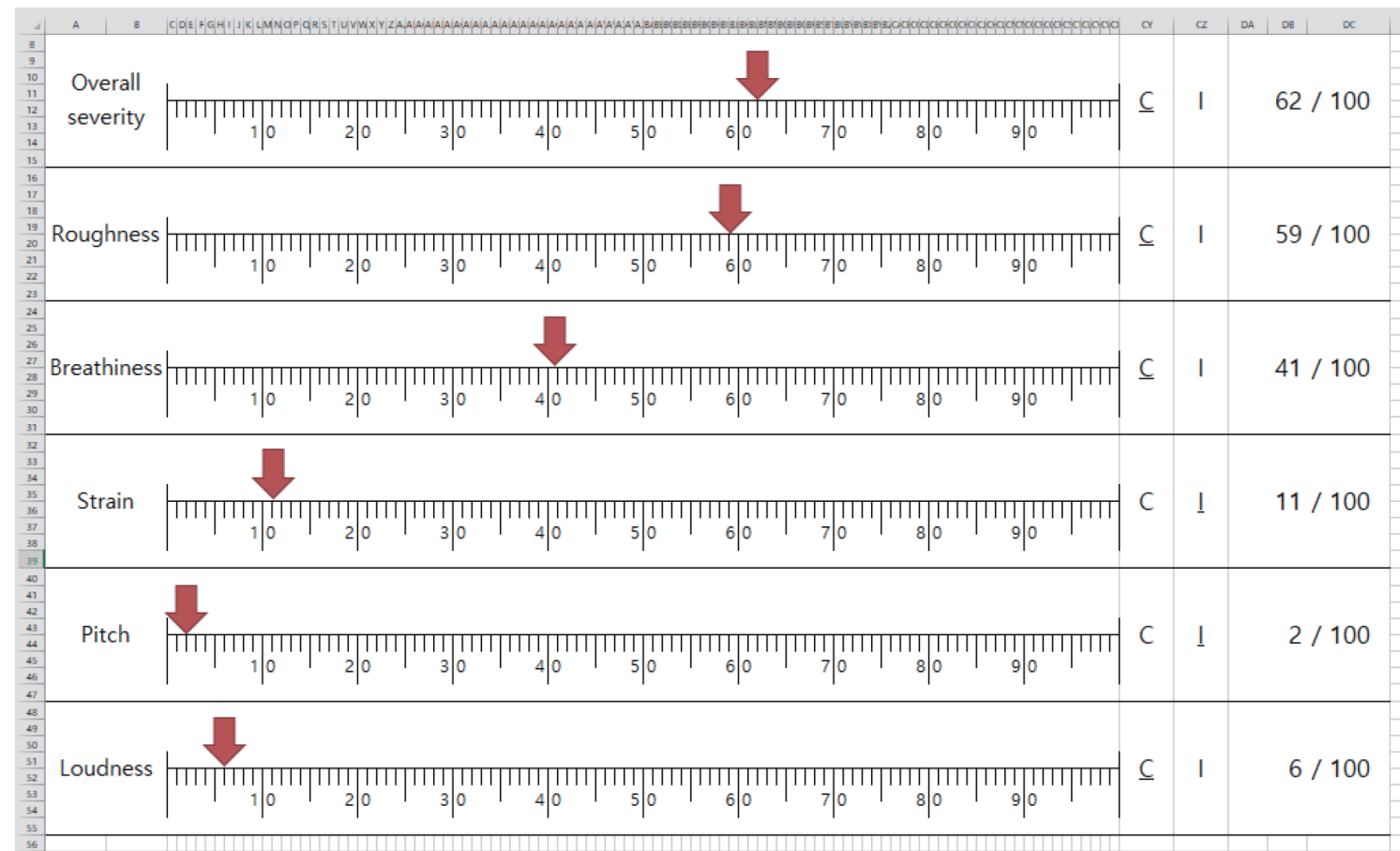

Fig. 1. Example of a customized Excel sheet for auditory-perceptual evaluation using the Consensus Auditory-Perceptual Evaluation of Voice form.

문장의 켑스트럼 피크 현저성(cepstral peak prominence, $\mathrm{CPP})$ 을 비교한 결과 뒷부분에서 감소하는 경향이 있었고[41], 정상 성인에서도 뒤로 갈수록 남성은 $\mathrm{CPP}$ 가 증가하는 반면, 여성은 감소하는 성별 차가 보고된 바 있다[42]. 즉 문단의 앞 부분에서 드러나지 않던 환자의 음성증상이나 특히 음성피 로(vocal fatigue)가 뒷부분에 이르러서야 발현할 가능성이 있으며, 실제 그러한 임상사례들이 자주 관찰된다는 의견도 있다. 만약 임상에서 가장 빈번하게 활용되는 기기 중 하나인 Computerized Speech Lab (CSL)을 활용한다면, 60초의 시 간제한이 있는 Real-Time EGG Analysis (Model 6103; KayPENTAX, Lincoln Park, NJ, USA)나 Real-Time Pitch (Model 5121; KayPENTAX) 프로그램에서 직접 녹음하기보다는, 시간 제한을 훨씬 길게 설정할 수 있는 CSL Main Program (Model 4150B; KayPENTAX)에서 녹음을 시행한 뒤 개별 분석 프로그램에서 로드하여 분석을 시행하기를 권한다.

문단 형태의 우리말 자료 외에도 최근 Choi[43]는 기존 표 준 문단의 음소 구성과 한국어의 음소 빈도수 등을 종합적으 로 고려하여 음성장애 환자의 음질 평가를 위한 표준문장을 개발하여 보고하였다. 이 문장들은 총 여섯 개이며, $\mathrm{CAPE}-\mathrm{V}$ 의 표준 프로토콜과 마찬가지로 모든 한국어의 단모음이 포 함된 문장, '흐으로 시작되는 문장, 모두 유성음으로 된 문장, 강한 성대접촉을 유도하는 문장, 비음이 포함된 문장, 무성파 열음이 가중된 문장 등을 포함함으로써 다양한 음소적 맥락 (phonetic context)을 구비하면서도 개별 음성질환의 특성을 잘 드러내는 데 기여할 수 있으므로 임상에서 활발한 사용이 권고된다. 예컨대 무성파열음이 가중된 문장에서는 무성음을 산출하다가 발성이 시작되는 이행부(transition)에서의 음성 일탈 양상을 관찰할 수 있고, 비음이 포함된 문장에서는 과 소비성(hyponasality)을 잘 관찰할 수 있다.

한편 아동은 표준화된 문구를 사용하지 않는 경우가 가장 많았고(69\%), 성인과 동일한 자료를 사용하거나(17\%), 자체 제작한 문단을 사용하거나(10\%), 자기소개를 활용(3\%)하는 것으로 나타났으며[40], 본 패널들도 대부분 이에 준하여 평 가하는 것으로 나타났다. 말 산출 기제의 구조적, 기능적 발달 과정을 거치고 있는 아동은 그 발달 수준에 따라 말 산출 특 성이 영향을 받을 수 있다. 이를 반영하기 위한 한 가지 방법 으로는 조음(articulation) 측면에 대한 국내 표준화 검사도 구, 가령 우리말조음음운검사2 (UTAP2)[44]나 아동용 발음 평가(APAC)[45]의 연결발화 자료를 청지각적인 평가에 활용 하면 한번에 말 차원에 대한 종합적인 검사가 가능하다. 긴 연 결발화를 한번에 자발적으로 혹은 모방하여 산출하기 어려 운 아동은 검사자가 짧은 단위로 따라 말하게 한 뒤 추후 음 성샘플을 Praat 등[46] 무료 소프트웨어를 통해 편집하여 검 사자의 발화를 삭제하면 아동의 연결발화 샘플을 구축하여 청지각적 평가나 음향학적 분석에도 활용할 수 있다.

최근 각 클리닉에서는 여러 음성질환 치료나 갑상선 수술 
등을 위해 내원하는 외국인 환자들을 흔히 만나볼 수 있다. 이 환자들에게 모음이나 자기소개 등 자발적인 발화 이외에 문단 읽기와 같은 일정한 말 자료를 사용하고자 할 때 어려 움이 있을 수 있다. 영어의 경우 언어병리학 분야에서 흔히 사 용되는 'Grandfather passage, 'Rainbow passage, 'Caterpillar passage' 등 다양한 문단자료들이 있지만[47-49], 그 외의 외국어들은 검색이나 사용이 여의치 않을 수 있다. 이때 유 용하게 사용할 수 있는 것은 전 세계적으로 가장 널리 사용되 는 음성장애지수(Voice Handicap Index, VHI) 설문지[50] 번안본의 각 문항을 순서대로 읽게 하는 것이다. VHI는 중국 어[51], 일본어[52], 독일어[53], 포르투갈어[54], 이탈리아어[55] 등 다양한 언어로 번안 및 표준화되어 있다. 러시아어의 경우 러시아어판 위키피디아(https://ru.wikipedia.org/)의 '톨스토 이'에 대한 소개 글 등의 일부 혹은 전체를 이용할 수 있다.

이러한 말 자료들은 통상적으로 환자가 편안하게 말을 산 출하는 조건을 가정하며, 대부분 평서문으로 된 문장을 활용 한다. 그러나 사실 일상생활이나 사회생활에서 환자는 직업, 환경, 성격 등에 따라 소리 지르기, 질문하기, 작게 말하기 등 다양한 형태의 발화를 산출하며, 보통의 발화와는 다른 조건 에서 더 큰 불편함을 호소하는 사례가 매우 빈번하다. 따라서 이러한 부분들을 종합적으로 파악하는 것은 환자의 일상생 활에서의 음성장애, 나아가 이를 고려한 치료효과 증대와 일 반화 효과 극대화에 매우 중요하다. 이러한 맥락에서 최근 말 범위 프로파일(speech range profile)에 대한 국내 한 연구에 서는 다양한 발화 조건을 가정한 말 자료가 개발되어 타당성 이 검증되었으므로 청지각적 평가에 활용해봄직하다(Supplementary Material 1 in the online-only Data Supplement)[56]. 예컨대 큰 소리를 유도하기 위해 “불이야! 불이야!” 와 같이 큰 소리로 발성하는 부분이 포함되어 있으며, '속삭이 지 말고 최대한 작은 소리로' 발화하는 부분, 의문형 문장 등 다양한 발화 조건이 포함되어 있다. 다만 “불이야!” 하고 소리 치는 부분과 같이 다른 환자에게 불안감을 줄 우려가 있는 경우, 검사실 방음에 주의하고 적절한 문구를 통해 검사 절차 에 의한 것임을 알리는 것이 좋다는 패널 의견이 있었다.

\section{음성질환의 특성에 맞는 청지각적 평가의 필요성}

환자들이 가진 음성질환에 따라 GRBAS나 CAPE-V 등의 양적인 평가만을 통해서는 온전히 기술하기 어려운 음성장애 군이 존재한다. 이러한 특성은 개별적으로 기술할 필요가 있 으며, 의료진과의 긴밀한 의사소통을 통해 잘 전달함으로써 정확한 조기진단과 환자에게 맞는 개별화된 중재서비스가 제 공되도록 힘써야 한다는 데에 본 패널들도 모두 동의하였다. 이러한 질환 중 대표적인 것이 연축성 발성장애이다.
연축성 발성장애의 경우 면밀한 면담을 통한 일상에서의 증상을 확인함과 동시에 특화된 말 자료를 사용하고, 음성 진 전(vocal tremor)의 동반 여부나 특정 조건에서의 개선 정도 를 파악하는 등 부가적인 노력을 기울일 필요가 있다[57]. 청 지각적 평가 시 전반적인 중증도뿐만 아니라 노력성, 강도의 변이 혹은 흔들림(oscillation), 음성의 끊김, 음성 진전, 조조 성, 기식성, 무력성 등을 살펴야 하며[58], 증상이 간헐적인지, 일관되게 나타나는지 관찰하여 근긴장성 발성장애와 감별해 야 한다[59]. 말 자료로는 유성음과 무성음을 주로 포함한 말 을 산출하게 하여 둘 간의 간극이 있는지 살펴보고, 모음과 말 자료 간의 중증도 차이를 살펴보며, 소리 지르기, 고음 산출, 숫자 세기 등의 과제에서 그 양상을 살펴보도록 권고된다[5760]. 앞서 언급한 표준문장에서도 유성음과 무성음 각각을 주로 포함한 문장들이 있는데, 이 문장들을 통해 연축성 발성 장애 중 내전형(adduction type)과 외전형(abduction type)을 감별 진단하는 데 도움을 받을 수 있다[57]. 즉 내전형의 경우 주로 유성음으로 된 문장 산출 시 음성의 끊김이 관찰되는 반 면, 외전형의 경우 무성 자음이 통상적인 길이보다 연장 산출 되는 양상(prolonged voiceless consonants)을 주로 보인다. 또한 앞서 언급한 '불이야' 문단도 고음 산출 시 증상이 완화 되는 내전형 연축성 발성장애의 특성을 감별하는 일정한 프 로토콜의 일부로 활용될 수 있다.

\section{공명, 조음 및 운율 측면}

\section{음성의 청지각적 평가 시 공명 평가의 필요성}

음성장애에서 공명 문제가 동반되는 경우는 매우 빈번하 다. 알레르기 비염 혹은 비중격만곡증 환자에서 청지각적으 로 과소비성이 관찰되는 것이 대표적이다. 이 경우 구강을 통 한 호흡으로 인하여 후두 전반의 적절한 습윤이 방해받거나, 과도한 분비물이 만성적으로 후두에 자극을 주거나, 습관적 이고 빈번한 헛기침 등 보상적이고 과기능적인 행동으로 인해 음성이 악화될 수 있다. 또한 가수 등 엘리트 음성사용자의 삶의 질에도 심각한 영향을 줄 수 있으며, 과소비성이 심한 경우 비강음의 조음에까지 영향을 줄 수 있다[61,62]. 아울러 간혹 연인두문 폐쇄에 관여하는 근육 약화를 동반한 마비말 장애(dysarthria)를 보이는 신경퇴행성 질환(neurodegenerative disease) 환자의 경우 과다비성(hypernasality)을 동반 하는 경우가 있으므로 주의가 필요하다[63].

따라서 본 패널 토의에서도 대부분의 패널들이 공명의 특 징을 별도로 루틴하게 평가 및 기록하는 것으로 보고되었다. 통상적으로 고모음 $(/ /, \ldots$, T/)이 저모음(///)에 비해 비음 치가 높은 것이 정상에 해당되므로, 평가 시의 음소적 맥락 
또한 고려하여야 한다. 최근에는 COVID-19 팬데믹 상황으 로 음성 클리닉에 내원하는 환자들이 마스크를 착용하여 공 명 평가의 어려움이 크므로, 주의 깊게 관찰하되 기능적으로 나타나는 공명장애는 아닌지의 여부를 확인할 필요가 있다 는 패널 의견도 제시되었다.

\section{조음 측면의 영향}

조음 또한 말 산출에 있어서 가장 중요한 과정 중의 하나 이며 순서상으로는 발성 이후에 이루어지는 것이지만, 사실 상 말 산출의 각 과정들은 시간적 선후관계와 무관하게 서로 영향을 주고받는다고 보는 것이 합리적이다. 따라서 이에 대 한 면밀한 관찰 또한 중요하다. 예컨대 '발음이 뭉개지는 증상' 이나 발성장애를 주소를 가지고 이비인후과 음성 클리닉에 내 원하였는데 반복적인 말 산출 시 어눌한 말(slurred speech), 과다비성, 조음 및 운율 이상 등이 증가하면서 말 명료도(speech intelligibility)가 급격히 저하되는 피로 효과(fatigue effect)가 관찰되는 경우 중증 근무력증의 감별진단 포인트가 될 수 있 으므로 주의 깊은 관찰이 필요하다[64,65]. 또한 조음 문제가 심하여 발성이나 공명 차원에 영향을 주는 경우 적절하게 기 록하여 두는 것이 좋다는 데에 패널들이 동의하였다.

\section{운율 측면의 영향}

말의 초분절적인 특성을 아우르는 운율 측면은 흔히 음성 평가에서 간과하기 쉽다. 그러나 조금만 주의를 기울이면 청 지각적 평가만으로도 쉽게 지각되는 중요한 운율 특성들이 있다. 예컨대 과도하게 길거나 짧은 구(long/short phrases), 파킨슨병 환자에서 관찰되는 짧은 말 뭉침(short rushes of speech), 과도하게 빠르거나 느린 말 속도, 단조로운 음도 (monopitch)나 크기(monoloudness), 비유창성(dysfluency) 등에 면밀한 관찰과 기록이 필요하다[66]. 특히 앞서 언급한 중증 근무력증 가능성이 있는 환자나 청각장애를 동반한 환 자에 대해 주의가 필요하다고 할 수 있다.

간혹 임상에서는 개인적인 특이성을 보이는 운율이 도드 라져 전반적인 말 산출 기제의 상태를 정확하게 파악하는 데 방해요소가 되기도 한다. 예컨대 감성이 충만한 억양, 기도를 하는 것과 같은 억양, 아나운서와 같은 억양 등이 그것이다. 이 경우 대상자에게 최대한 평상시의 대화처럼 편안하게 발 화하도록 지시사항을 주는 것이 바람직하다는 데에 패널들이 동의하였다.

\section{결 론}

음성장애 환자에 대한 SLP의 청지각적 평가는 흔히 다면
적 음성평가에서 시금석으로 여겨지며, 여타 평가 양식에서 얻을 수 없는 중요한 정보를 제공한다. 그러한 만큼 SLP는 음 성뿐만 아니라 말 산출 기제 전반에 대한 종합적이고 면밀한 평가를 반드시 시행할 필요가 있으며, 이 과정에서 다양한 어 려움을 마주치게 된다. 또한 SLP는 주관적인 평가의 특성상 평가 대상자에 대한 편향을 피하고, 청지각적 특징별로 중증 도의 스펙트럼을 넓고 일정하게 유지하고자 노력해야만 한다. 마지막으로 전문의와 SLP 간의 긴밀한 의사소통을 통하여 각 환자의 중요한 정보를 적절하고 효율적인 방법으로 기록 및 전달함으로써 원활하고 긴밀한 팀 접근을 수행하는 일이 매우 중요하다 할 수 있다.

중심 단어: 음성장애; 발성장애; 청지각적 평가; 음질; 언어 재활사.

\section{Supplementary Materials}

The online-only Data Supplement is available with this article at https://doi.org/10.22469/jkslp.2021.32.3.109.

Acknowledgments

This work was supported by the Ministry of Education of the Republic of Korea and the National Research Foundation of Korea (NRF2018S1A5A2A03032902). The author thanks Prof. Seong Hee Choi (Daegu Catholic University) and Prof. Jaeock Kim (Kangnam University), SLPs Geun-Hyo Kim, PhD (Pusan National University Hospital), Yeon-Woo Lee, $\mathrm{PhD}$ (Pusan National University Hospital), In Hyo Seo, PhD (Dankook University Hospital), and Bo Ram Yun, MS (Hanyang University Seoul Hospital) for sharing their valuable clinical experiences and insightful comments at the panel discussion.

Conflicts of Interest

The author has no financial conflicts of interest.

\section{REFERENCES}

1. Ma EP, Yiu EM. Multiparametric evaluation of dysphonic severity. J Voice 2006;20(3):380-90.

2. Lee SJ, Choi HS, Kim H. A comparison of voice activity and participation profiles among etiological groups. J Voice 2019;33(5):804.e512.

3. Kim J. Auditory-perceptual evaluation. In: Korean Society of Laryngology, Phoniatrics and Logopedics, editors. Hu doo eum sung eon eo ui hak [Laryngology, Phoniatrics and Logopedics]. 2nd ed. Seoul: Panmun Education;2016. p.111-21.

4. Vance D, Heyd C, Pier M, Alnouri G, Sataloff RT. Paradoxical vocal fold movement: a retrospective analysis. J Voice 2020;35(6):927-9.

5. Ivancic R, Matrka L, Wiet G, Puckett A, Haney J, deSilva B. Reduced asthma medication use after treatment of pediatric paradoxical vocal fold motion disorder. Laryngoscope 2021;131(7):1639-46.

6. Gallena SK, Johnson AT, Vossoughi J. Short-term intensive therapy and outcomes for athletes with paradoxical vocal fold motion disorder. Am J Speech Lang Pathol 2019;28(1):83-95.

7. Schindler A, Bottero A, Capaccio P, Ginocchio D, Adorni F, Ottaviani F. Vocal improvement after voice therapy in unilateral vocal fold paralysis. J Voice 2008;22(1):113-8.

8. Korean Society of Laryngology, Phoniatrics and Logopedics Guideline Task Force; Ryu CH, Lee SJ, Cho JG, Choi IJ, Choi YS, Hong YT, et al. Care and management of voice change for thyroid surgery: Ko- 
rean Society of Laryngology, Phoniatrics and Logopedics clinical practice guideline. Clin Exp Otorhinolaryngol 2021 Jun 1 [Epub]. Available from: https://doi.org/10.21053/ceo.2021.00633.

9. Korean Society of Laryngology, Phoniatrics and Logopedics Guideline Task Force; Ryu CH, Kwon TK, Kim H, Kim HS, Park IS, Woo $\mathrm{JH}$, et al. Guidelines for the management of unilateral vocal fold paralysis from the Korean Society of Laryngology, Phoniatrics and Logopedics. Clin Exp Otorhinolaryngol 2020;13(4):340-60.

10. Bothe C, López M, Quer M, León X, García J, Lop J. Aetiology and treatment of vocal fold paralysis: Retrospective study of 108 patients. Acta Otorrinolaringol Esp 2014;65(4):225-30.

11. Misono S, Merati AL. Evidence-based practice: Evaluation and management of unilateral vocal fold paralysis. Otolaryngol Clin North Am 2012;45(5):1083-108.

12. Walton C, Conway E, Blackshaw H, Carding P. Unilateral vocal fold paralysis: A systematic review of speech-language pathology management. J Voice 2017;31(4):509.e7-22.

13. Hirano M. Clinical examination of voice. Wien; New York: SpringerVerlag;1981.

14. Kempster GB, Gerratt BR, Verdolini Abbott K, Barkmeier-Kraemer J, Hillman RE. Consensus auditory-perceptual evaluation of voice: Development of a standardized clinical protocol. Am J Speech Lang Pathol 2009;18(2):124-32.

15. Kim GH, von Latoszek BB, Lee YW. Validation of Acoustic Voice Quality Index version 3.01 and Acoustic Breathiness Index in Korean population. J Voice 2021;35(4):660.e9-18.

16. Choi SH, Yu M, Choi CH. Comparisons of 4-point GRBAS, 7-pointGRBAS, and CAPE-V for auditory perceptual evaluation of dysphonia. Audiol Speech Res 2021;17(2):206-19.

17. Karnell MP, Melton SD, Childes JM, Coleman TC, Dailey SA, Hoffman HT. Reliability of clinician-based (GRBAS and CAPE-V) and patient-based (V-RQOL and IPVI) documentation of voice disorders. J Voice 2007;21(5):576-90.

18. Bhuta T, Patrick L, Garnett JD. Perceptual evaluation of voice quality and its correlation with acoustic measurements. J Voice 2004;18(3): 299-304.

19. Dogan M, Eryuksel E, Kocak I, Celikel T, Sehitoglu MA. Subjective and objective evaluation of voice quality in patients with asthma. J Voice 2007;21(2):224-30.

20. Uloza V, Saferis V, Uloziene I. Perceptual and acoustic assessment of voice pathology and the efficacy of endolaryngeal phonomicrosurgery. J Voice 2005;19(1):138-45.

21. Sahin M, Gode S, Dogan M, Kirazli T, Ogut F. Effect of voice therapy on vocal fold polyp treatment. Eur Arch Otorhinolaryngol 2018;275(6): 1533-40.

22. Seo IH, Moon JH, Chung PS, Lee SJ. Role and effectiveness of postoperative voice therapy in laryngeal microsurgery. Korean J Otorhinolaryngol-Head Neck Surg 2018;61(4):200-7.

23. Bauer V, Aleric Z, Jancic E, Knezevic B, Prpic D, Kacavenda A. Subjective and perceptual analysis of voice quality and relationship with neurological disfunction in multiple sclerosis patients. Clin Neurol Neurosurg 2013;115 Suppl 1:S17-20.

24. Zraick RI, Kempster GB, Connor NP, Thibeault S, Klaben BK, Bursac $Z$, et al. Establishing validity of the consensus auditory-perceptual evaluation of voice (CAPE-V). Am J Speech Lang Pathol 2011;20(1): 14-22.

25. Awan SN, Roy N, Zhang D, Cohen SM. Validation of the Cepstral Spectral Index of Dysphonia (CSID) as a screening tool for voice disorders: Development of clinical cutoff scores. J Voice 2016;30(2):130-44.

26. Awan SN, Solomon NP, Helou LB, Stojadinovic A. Spectral-cepstral estimation of dysphonia severity: External validation. Ann Otol Rhinol Laryngol 2013;122(1):40-8.

27. Lee SJ, Choi HS, Kim H. Acoustic Psychometric Severity Index of Dysphonia (APSID): Development and clinical application. J Voice 2021;35(4):660.e19-25.

28. Lee Y, Park H, Bae I, Kim G. The usefulness of multi voice evaluation: Development of a model for predicting a degree of dysphonia. J Voice 2020 Nov 13 [Epub]. Available from: https://doi.org/10.1016/j. jvoice.2020.10.020.

29. Helou LB, Solomon NP, Henry LR, Coppit GL, Howard RS, Stojadinovic A. The role of listener experience on Consensus Auditory-perceptual Evaluation of Voice (CAPE-V) ratings of postthyroidectomy voice. Am J Speech Lang Pathol 2010;19(3):248-58.

30. Lee Y, Kim G, Kwon S. The usefulness of auditory perceptual assessment and acoustic analysis for classifying the voice severity. J Voice 2020;34(6):884-93.

31. Ma E, Yiu E. Handbook of voice assessments. San Diego: Plural Publishing, Inc.;2011.

32. Chen Z, Fang R, Zhang Y, Ge P, Zhuang P, Chou A, et al. The Mandarin version of the Consensus Auditory-Perceptual Evaluation of Voice (CAPE-V) and its reliability. J Speech Lang Hear Res 2018;61(10):2451-7.

33. de Almeida SC, Mendes AP, Kempster GB. The Consensus AuditoryPerceptual Evaluation of Voice (CAPE-V) psychometric characteristics: II European Portuguese version (II EP CAPE-V). J Voice 2019;33(4): 582.e5-13.

34. Ertan-Schlüter E, Demirhan E, Ünsal EM, Tadıhan-Özkan E. The Turkish version of the Consensus Auditory-Perceptual Evaluation of Voice (CAPE-V): A reliability and validity study. J Voice 2020; 34(6):965.e13-22.

35. Brinca L, Batista AP, Tavares AI, Pinto PN, Araújo L. The effect of anchors and training on the reliability of voice quality ratings for different types of speech stimuli. J Voice 2015;29(6):776.e7-14.

36. Dos Santos PCM, Vieira MN, Sansão JPH, Gama ACC. Effect of auditory-perceptual training with natural voice anchors on vocal quality evaluation. J Voice 2019;33(2):220-5.

37. Mozzanica F, Ginocchio D, Borghi E, Bachmann C, Schindler A. Reliability and validity of the Italian version of the Consensus Auditory-Perceptual Evaluation of Voice (CAPE-V). Folia Phoniatr Logop 2013;65(5):257-65.

38. Núñez-Batalla F, Morato-Galán M, García-López I, Ávila-Menéndez A. Validation of the Spanish adaptation of the Consensus AuditoryPerceptual Evaluation of Voice (CAPE-V). Acta Otorrinolaringol Esp (Engl Ed) 2015;66(5):249-57.

39. Khoramshahi H, Khatoonabadi AR, Khoddami SM, Dabirmoghaddam P, Ansari NN. Responsiveness of Persian version of Consensus Auditory Perceptual Evaluation of Voice (CAPE-V), Persian version of voice handicap index (VHI), and Praat in vocal mass lesions with muscle tension dysphonia. J Voice 2018;32(6):770.e21-30.

40. Choi SH. Speech-language pathologists' voice assessment and voice therapy practices: A survey for standard clinical guideline and evidence-based practice. Commun Sci Disord 2013;18(4):473-85.

41. Lee SJ, Lim SE, Choi HS. A comparison of cepstral and spectral measures according to measurement position in a reading passage. Commun Sci Disord 2017;22(4):818-26.

42. Lee SJ, Pyo HY, Choi HS. Normative data of cepstral and spectral measures in Korean adults using vowel phonation and passage reading tasks. Commun Sci Disord 2018;23(1):208-16.

43. Choi SH. Development of Korean standardized sentences on voice quality evaluation for dysphonia. Audiol Speech Res 2018;14(2):12842 .

44. Kim Y, Shin M, Kim S, Ha J. Urimal Test of Articulation and Phonology 2 (UTAP2). Seoul, Korea: Hakjisa;2020.

45. Kim M, Pae S, Park C. Assessment of phonology \& articulation for children (APAC). Incheon, Korea: Human Brain Research \& Consulting Co.;2007.

46. Boersma P, Weenink D. Praat: Doing phonetics by computer (version 6.1.48) [Computer program]. Amsterdam, the Netherlands: University of Amsterdam, Phonetic Sciences Department: [updated 2021 
June 12; cited 2021 June 12]. Available from: http://www.praat.org/. 47. Zraick RI, Wendel K, Smith-Olinde L. The effect of speaking task on perceptual judgment of the severity of dysphonic voice. J Voice 2005; 19(4):574-81.

48. Fairbanks G. Voice and articulation drillbook. 2nd ed. New York: Harper \& Row;1960.

49. Patel R, Connaghan K, Franco D, Edsall E, Forgit D, Olsen L, et al. "The Caterpillar": A novel reading passage for assessment of motor speech disorders. Am J Speech Lang Pathol 2013;22(1):1-9.

50. Jacobson BH, Johnson A, Grywalski C, Silbergleit A, Jacobson G, Benninger MS, et al. The voice handicap index (VHI): Development and validation. Am J Speech Lang Pathol 1997;6(3):66-70.

51. Xu W, Han D, Li H, Hu R, Zhang L. Application of the Mandarin Chinese version of the voice handicap index. J Voice 2010;24(6):702-7.

52. Taguchi A, Mise K, Nishikubo K, Hyodo M, Shiromoto O. Japanese version of voice handicap index for subjective evaluation of voice disorder. J Voice 2012;26(5):668.e15-9.

53. Nawka T, Wiesmann U, Gonnermann U. Validation of the German version of the voice handicap index. HNO 2003;51(11):921-30.

54. Behlau M, Alves Dos Santos Lde M, Oliveira G. Cross-cultural adaptation and validation of the voice handicap index into Brazilian Portuguese. J Voice 2011;25(3):354-9.

55. Schindler A, Ottaviani F, Mozzanica F, Bachmann C, Favero E, Schettino I, et al. Cross-cultural adaptation and validation of the Voice Handicap Index into Italian. J Voice 2010;24(6):708-14.

56. Kim J, Lee SJ. Development and validation of Speech Range Profile task. Phon Speech Sci 2019;11(3):77-87.

57. Ludlow CL, Adler CH, Berke GS, Bielamowicz SA, Blitzer A, Bressman SB, et al. Research priorities in spasmodic dysphonia. Otolaryngol Head Neck Surg 2008;139(4):495-505.
58. Rojas GVE, Ricz H, Tumas V, Rodrigues GR, Toscano P, Aguiar-Ricz L. Vocal parameters and self-perception in individuals with adductor spasmodic dysphonia. J Voice 2017;31(3):391.e7-18.

59. Hintze JM, Ludlow CL, Bansberg SF, Adler CH, Lott DG. Spasmodic dysphonia: A review. Part 2: Characterization of pathophysiology. Otolaryngol Head Neck Surg 2017;157(4):558-64

60. Ludlow CL, Domangue R, Sharma D, Jinnah HA, Perlmutter JS, Berke G, et al. Consensus-based attributes for identifying patients with spasmodic dysphonia and other voice disorders. JAMA Otolaryngol Head Neck Surg 2018;144(8):657-65.

61. Hamdan AL, Sibai A, Youssef M, Deeb R, Zaitoun F. The use of a screening questionnaire to determine the incidence of allergic rhinitis in singers with dysphonia. Arch Otolaryngol Head Neck Surg 2006;132(5):547-9.

62. Ohlsson AC, Drevsäter A, Brynnel M, Johansson I. Allergic rhinitis and voice change. Logoped Phoniatr Vocol 2016;41(4):143-8.

63. Green JR, Yunusova Y, Kuruvilla MS, Wang J, Pattee GL, Synhorst L, et al. Bulbar and speech motor assessment in ALS: Challenges and future directions. Amyotroph Lateral Scler Frontotemporal Degener 2013; 14(7-8):494-500.

64. Nemr NK, Simões-Zenari M, Ferreira TS, Fernandes HR, Mansur LL. Dysphonia as the primary complaint in a case of myasthenia gravis: Diagnosis and speech therapy. Codas 2013;25(3):297-300.

65. Wenke RJ, Goozee JV, Murdoch BE, LaPointe LL. Dynamic assessment of articulation during lingual fatigue in myasthenia gravis. J Med Speech Lang Pathol 2006;14(1):13-32.

66. Stewart C, Winfield L, Hunt A, Bressman SB, Fahn S, Blitzer A, et al. Speech dysfunction in early Parkinson's disease. Mov Disord 1995; 10(5):562-5. 


\section{Supplementary Material 1}

The "Fire!" paragraph developed for the speech range profile task

화재가 발생하면 어떻게 해야 할까요?

불이 나면 침착하게 대처합니다.

불을 발견하면 먼저 최대한 큰 소리로 외쳐 주변에 알려주세요.

(최대한 큰 소리로) "불이야! 불이야!"

다음은 화재 경보 비상벨을 누르고 119에 신고 후 대피합니다.

젖은 수건 등으로 코와 입을 막고 낮은 자세로 이동합니다.

엘리베이터는 절대 사용하지 마세요.

(속삭이지 말고 최대한 작은 소리로) 엘리베이터는 절대 사용하지 마세요.

계단으로 빨리빨리 대피합시다.

아래쪽 대피가 불가능하다고 의심되면 위쪽 옥상으로 대피할 것을 권합니다.

대피가 어렵다고 예상되면 문틈을 막고 구조를 기다리는 것이 유리합니다.

이해가 잘 되셨나요?

불이 나면 침착하게 대처합니다.

(최대한 큰소리로) “불이야! 불이야!” 